$$
\operatorname{CON} F-961202-20
$$

\title{
FERROMAGNETIC NANOCOMPOSITE FILMS FROM THERMALLY LABILE NITRIDE PRECURSORS
}

L. Maya*, M. Paranthaman*, J.R. Thompson*, T. Thundat*, and R.J. Stevenson**

* Oak Ridge National Laboratory, P.O.B. 2008, Oak Ridge TN 37831.

** K-25 Plant, P.O.B. 2008, Oak Ridge TN 37831.

"The submitted manuscript has been authored by a contractor of the U.S. Government under contract No. DE-AC05-96OR22464. Accordingly, the U.S. Government retains a nonexclusive, royalty-free license to publish or reproduce the published form of this contribution, or allow others to do so, for U.S. Govermment purposes."

DIGTHIBUTION OF THIS DOCUMENT IS UNUIATEEE

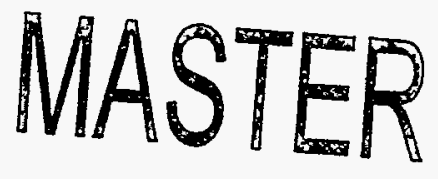




\section{DISCLAIMER}

This report was prepared as an account of work sponsored by an agency of the United States Government. Neither the United States Government nor any agency thereof, nor any of their employees, makes any warranty, express or implied, or assumes any legal liability or responsibility for the accuracy, completeness, or usefulness of any information, apparatus, product, or process disclosed, or represents that its use would not infringe privately owned rights. Reference herein to any specific commercial product, process, or service by trade name, trademark, manufacturer, or otherwise does not necessarily constitute or imply its endorsement, recommendation, or favoring by the United States Government or any agency thereof. The views and opinions of authors expressed herein do not necessarily state or reflect those of the United States Government or any agency thereof. 


\section{DISCLAIMER}

Portions of this document may be illegible in electronic image products. Images are produced from the best available original document. 


\title{
FERROMAGNETIC NANOCOMPOSITE FLMS FROM THERMALLY LABHE NITRIDE PRECURSORS
}

\author{
L. MAYA*,M. PARANTHAMAN*, J.R. THOMPSON*, T. THUNDAT*, and R.J. \\ STEVENSON** \\ * Oak Ridge National Laboratory, P.O. B. 2008, Oak Ridge TN 37831. \\ ** K-25 Plant, P.O.B. 2008, Oak Ridge TN 37831.
}

\section{ABSTRACT}

A series of nanocomposite films containing nickel or cobalt nitride dispersed in a ceramic matrix of aluminum nitride, boron nitride or silicon nitride, were prepared by reactive sputtering of selected alloys or compounds such as nickel aluminide or cobalt silicide. Thermal treatment of the nitride composites in vacuum at $\leq 500{ }^{\circ} \mathrm{C}$ leads to selective loss of nitrogen from CoN or $\mathrm{Ni}_{3} \mathrm{~N}$ to generate dispersions of the metal in the ceramic matrix. This treatment may be performed in a localized manner by means of a focused laser beam to generate microscopic features that are imaged by magnetic force microscopy. The films are potentially useful for data storage with superior chemical and mechanical stability provided by the ceramic matrix and high encoding density made possible because of the size of the magnetic particles of less than $10 \mathrm{~nm}$ generated in the thermal treatment. The films were characterized by chemical and physical means including FTIR, TEM, MFM and magnetic measurements. Preliminary results on similar iron composites are also described.

\section{INTRODUCTION}

Nanocomposite films, described initially as granular solids, have been the subject of many studies since the pioneering work of Abeles et al[1] who studied transport properties of very small gold particles in silica as a function of metal loading. Interest in this area of research is driven by theoretical and practical considerations since these materials may show optical, electrical, magnetic or mechanical properties that depart from those shown by conventional solids containing particles with dimensions $\geq 50 \mathrm{~nm}$. A promising area for development is the use of ferromagnetic nanocomposites as data recording media. The properties of such media may be manipulated by controlling the size and volume fraction of the ferromagnetic particles in the matrix. An additional advantage inherent in the configuration of nanocomposite films is that the matrix provides, if properly chosen, chemical and mechanical protection for the metal particles. A recent review by Chien[2] gives a description of the principles controlling the complex relationship of particle size and temperature on the magnetic characteristics of ferromagnetic nanocomposites as well as a phenomenological account of a variety of systems. Nanocomposites, in general, are conveniently prepared by sputtering of multiple homogeneous targets as done by Abeles et al[1] or through reactive sputtering of alloys and compounds[3]. Alternate approaches are sol-gel techniques[4] and ion implantation[5].

\section{EXPERIMENT}

Film deposition was conducted in a parallel plate glow discharge apparatus previously described[6]. In a typical experiment, a target such as nickel aluminide was subjected to reactive sputtering for a period of about 20 hours in a nitrogen plasma generated by a potential drop of 
$500 \mathrm{~V}$ and a current density of $1.8 \mathrm{~mA} / \mathrm{cm}^{2}$. Films, a few micron thick, were deposited on a variety of substrates by passing $10 \mathrm{ml} / \mathrm{min}$ of nitrogen while maintaining a pressure of 2 torr in the system. Characterization was performed with a variety of physical and chemical techniques including temperature programmed thermal decomposition (TPTD), conducted under vacuum using a $10^{\circ} \mathrm{C} / \mathrm{min}$ ramp with a mass analyzer on line to derive a profile of volatile evolution as a function of temperature. Also performed were direct chemical analyses, XRD, TEM, and FTIR. Magnetic characterization was conducted with a superconducting quantum interference device (SQUID) magnetometer in the temperature range of 5-300 K using a field of up to $65 \mathrm{kOe}$; in addition to this, microscopic imaging was also obtained by magnetic force microscopy (MFM).

\section{RESULTS AND DISCUSSION}

\section{Thermal properties}

Central to the development of the nanocomposite systems examined in this study are the thermal properties of the ferromagnetic metal nitrides utilized as precursors. Their relatively limited stability allows selective decomposition at moderate temperatures, $\sim 600{ }^{\circ} \mathrm{C}$, while the ceramic matrix is unaffected. The thermal decomposition of pure $\mathrm{CoN}$ and FeN was examined by Suzuki et al $[7,8]$ who conducted annealing treatments in a stepwise manner; on the other hand, the thermal decomposition of pure $\mathrm{Ni}_{3} \mathrm{~N}$ was examined[6] using a continuous incremental ramp. Pure $\mathrm{Co}$ and $\mathrm{Fe}$ foils were sputtered in the present study to confirm the stoichiometry of the products formed under the experimental conditions described above. The nitrides produced in both cases were the ones with a 1:1 stoichiometry. Both elements form nitrides with lower nitrogen content, $\mathrm{Co}_{2} \mathrm{~N}$ and $\mathrm{Co}_{3} \mathrm{~N}$ in the case of cobalt, and in the case of iron, $\mathrm{Fe}_{4} \mathrm{~N}$ as a additional phases. The thermal decomposition profile of CoN shows two nitrogen evolution events at 340 and $400{ }^{\circ} \mathrm{C}$. The integrated areas for the two events are approximately equal, suggesting a stepwise decomposition to $\mathrm{Co}_{2} \mathrm{~N}$ in the first step and formation of metallic cobalt in the second step. The profile is given in Fig. 1 along with the result of a run that was quenched halfway to establish weight loss and to examine the crystalline phase present at that stage.

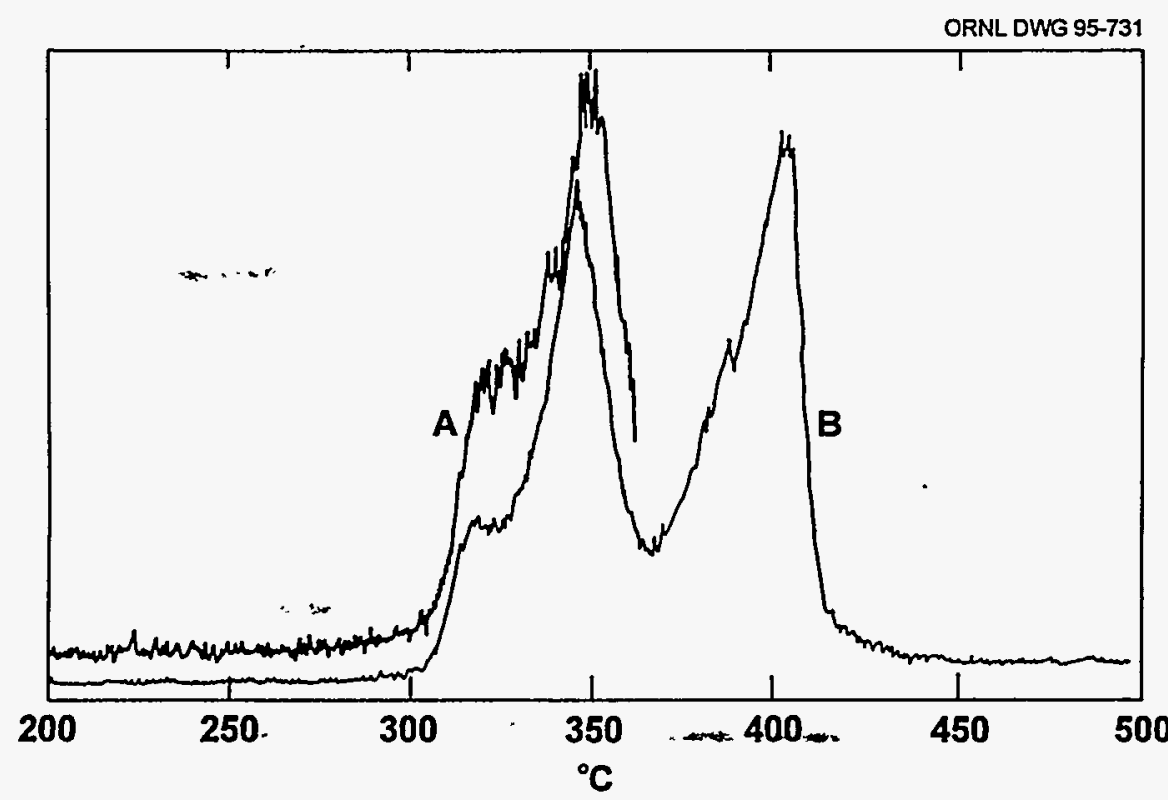

Fig. 1. Thermal decomposition profile, showing mass analyzer response to ion $m / e=28$. Trace $A$ decomposition of pure CoN quenched. Trace B pure CoN. 
Weight loss in the quenched experiment corresponded to $9.7 \mathrm{wt} \%$ of the initial which is approximately half of the theoretical nitrogen content of CoN of 19.2\%. XRD however showed both $\mathrm{Co}_{2} \mathrm{~N}$ and $\mathrm{Co}_{3} \mathrm{~N}$. The decomposition profile of $\mathrm{Ni}_{3} \mathrm{~N}$, (no higher nitrides are formed) also exhibits two events at 300 and $380^{\circ} \mathrm{C}$. The intermediate step corresponds to the formation of $\mathrm{Ni}_{4} \mathrm{~N}$. Finally, $\mathrm{FeN}$ also decomposes in two steps to yield initially $\mathrm{Fe}_{2} \mathrm{~N}$ with a maximum volatile evolution at $480{ }^{\circ} \mathrm{C}$ and a second step which reaches a maximum at $565^{\circ} \mathrm{C}$ but in this case the evolution tails off to temperatures higher than $650{ }^{\circ} \mathrm{C}$ reflecting the higher thermal stability of $\mathrm{Fe}_{4} \mathrm{~N}$.

The decomposition profiles of all the nanocomposite films studied, $\mathrm{Ni} 3 \mathrm{~N} / \mathrm{AIN}, \mathrm{CoN} / \mathrm{Si}_{3} \mathrm{~N}_{4}$, $\mathrm{CoN} / \mathrm{BN}$, and $\mathrm{FeN} / \mathrm{Si}_{3} \mathrm{~N}_{4}$ exhibit similar patterns to the pure metal nitride compounds. The $\mathrm{x}$-ray diffraction of the nanocomposite films identified the metal nitride as the only crystalline phase. There was significant line broadening which was used to calculate an average particle size that turned out to be $<10 \mathrm{~nm}$ in every case. A very significant characteristic of these systems is that the particle size of metal produced by the thermal treatment does not show any crystal grain growth, probably due to the ceramic matrix which prevents aggregation. This is illustrated in Fig. 2 for the cobalt nitride system. The presence of the ceramic matrix in each composite was revealed by their corresponding typical infrared spectra and also confirmed by direct chemical analysis.

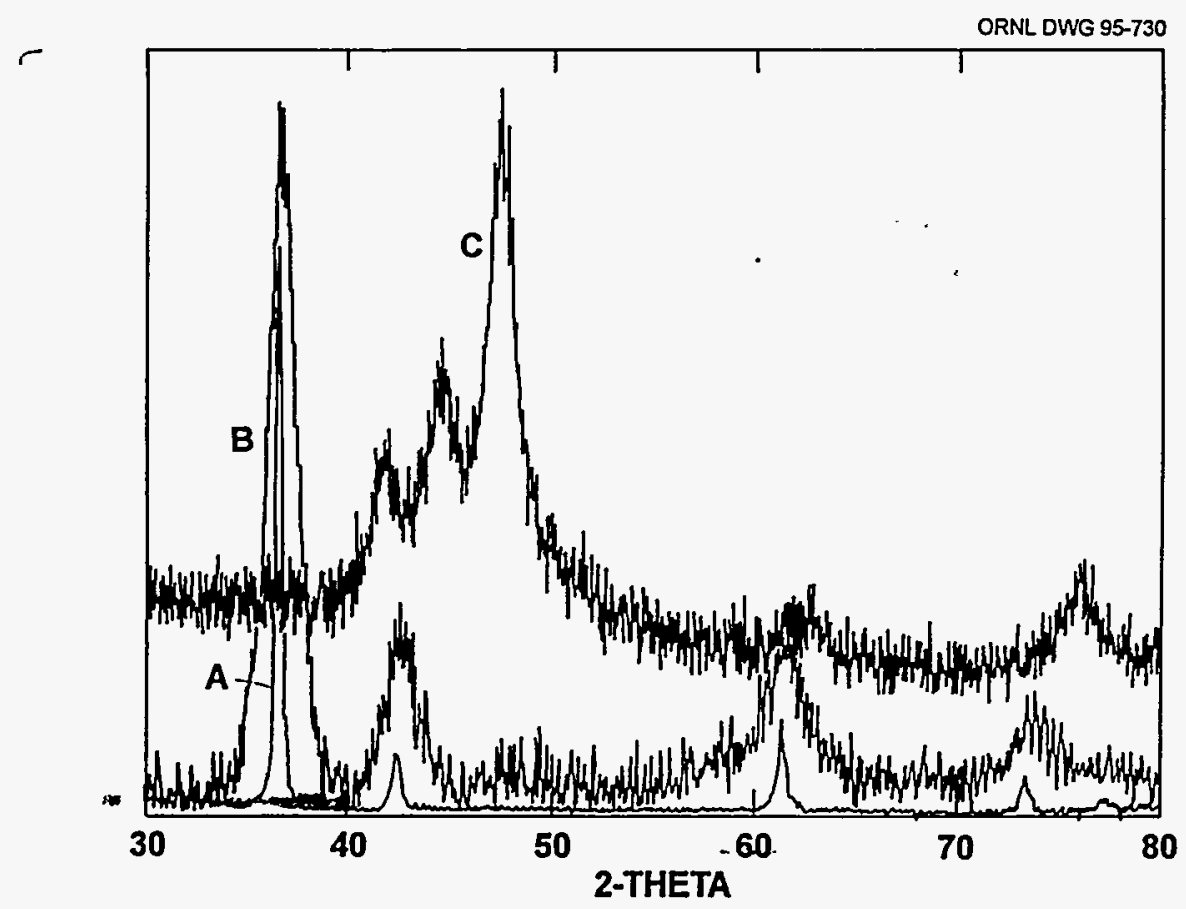

Fig.2 Diffraction patterns of (A) pure crystalline CoN, (B) CoN/BN nanocomposite, and (C) pyrolysis product, pattern corresponds to hcp cobalt.

\section{Magnetic properties}

The magnetic properties of the nitride nanocomposites were examined. Nickel nitride, $\mathrm{Ni}_{3} \mathrm{~N}$, dispersed in aluminum nitride, is paramagnetic, the slope $\mathrm{dM} / \mathrm{dH}$ increased from $2 \times 10^{-5}$ $\mathrm{cm}^{3} / \mathrm{g}$ of Ni at $200 \mathrm{~K}$ to $6 \times 10^{-5} \mathrm{~cm}^{3} / \mathrm{g}$ of Ni at $5 \mathrm{~K}$. Cobalt nitride, CoN, dispersed in boron nitride, is also paramagnetic. The corresponding values for $200 \mathrm{~K}$ and $30 \mathrm{~K}$ were $2.1 \times 10^{-5}$ and $1.1 \times 10^{-4} \mathrm{~cm}^{3} / \mathrm{g}$ of $\mathrm{Co}$, respectively. Suzuki et al[7] found paramagnetic susceptibilities for pure 
CoN that are significantly smaller $(\sim 1 / 10)$ than the values given above; this difference may stem from the nanostructure of the composite. Iron nitride, is non-ferromagnetic at room temperature and antiferromagnetic at temperatures below $100 \mathrm{~K}$ [8]. Our study of the iron nitride composite is still in progress.

Saturation magnetization of the ferromagnetic nanocomposites derived from the thermal treatment were to about $74 \%$ of that for pure metal for Ni/AIN. The corresponding figures are $94 \%$ for $\mathrm{Co} / \mathrm{BN}$ and $50 \%$ for of $\mathrm{Fe} / \mathrm{Si}_{3} \mathrm{~N}_{4}$. The lower saturation magnetization is common for nanostructured metals and has been explained as arising from the oxidation of the clusters and disorder at interfaces. The iron case is somewhat more complicated since the pyrolysis has to be conducted at temperatures above $700{ }^{\circ} \mathrm{C}$ to insure that all of the nitride is converted to the metal. Under those conditions, however reaction between the metal and the ceramic matrix is possible and silicides were formed which accounts in part for the lower saturation magnetization for iron.

In common with nanostructured ferromagnetic metals, the nanocomposites examined in this study showed hysteresis upon reversal of the field in a given temperature range. Typical results are illustrated in Fig 3 for the Co/BN system.

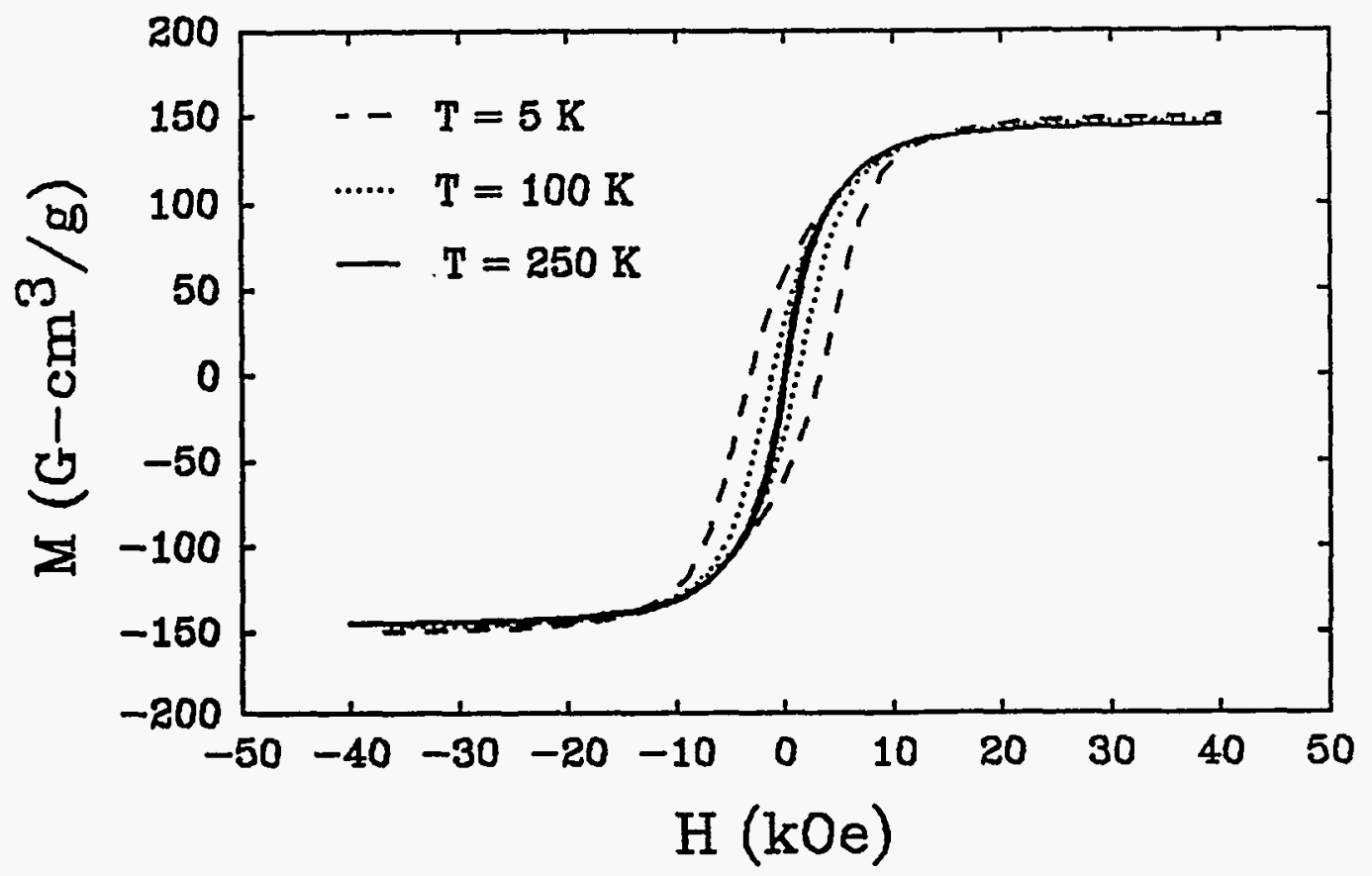

Fig. 3 Magnetization curves for $\mathrm{Co} / \mathrm{BN}$ nanocomposite

There are extensive experimental observations of size effects on coercivity and its temperature dependence that have been explained[9] in relation to the size of single-domain particles. Coercivity reaches a maximum for single domain particles but decreases both for larger particles that are multidomain and for smaller particles which fall within the realm of superparamagnetic behavior. Superparamagnetism is dependent on temperature and is evident above a critical temperature, the blocking temperature, $T_{B}$, above which thermal motions control the alignment of the assembly with the applied field and the system is magnetically reversible(coercive field, $\mathrm{H}_{C}=0$ ). The assembly is stable at temperatures lower than $\mathrm{T}_{\mathrm{B}}$ and the system shows hysteresis. Experimentally we derive $T_{B}$ from plots of $H_{C}$ vs $T^{1 / 2} \cdot T_{B}$ values are $392 \mathrm{~K}$ for Ni/AlN, $206 \mathrm{~K}$ for $\mathrm{Co} / \mathrm{BN}, 50 \mathrm{~K}$ for $\mathrm{Co} / \mathrm{Si}_{3} \mathrm{~N}_{4}$ and $100 \mathrm{~K}$ for $\mathrm{Fe} / \mathrm{Si}_{3} \mathrm{~N}_{4}$. The coercive field at room temperature for nickel is $35 \mathrm{Oe}$; on the other hand, the other systems should not show any coercivity at room temperature under ideal conditions since the $T_{B}$ values are much 
lower than ambient temperature, and indeed this is the case for the iron nanocomposite but the cobalt showed residual coercivity of about $30 \mathrm{Oe}$ in the silicon nitride matrix and 88 Oe in the boron nitride matrix. Similar departures from ideal behavior have been observed, among others. for nanocrystalline nickel[10] and are interpreted as being due to a transition from a regimen where crystal anisotropy energy dominates at low temperature to a regimen where shape anisotropy dominates at higher temperatures.

\section{Microscopy}

Examination of our films by Atomic Force Microscopy, AFM, and Magnetic Force Microscopy, MFM, reveals a botryoidal morphology, consisting of aggregates of smaller clusters. about $15 \mathrm{~mm}$ in diameter. The AFM and MFM images are similar, other than subtle differences in contrast, since the MFM responds to a field gradient generated by the presence of the ferromagnetic particles. This is illustrated in Fig. 4. The AFM and MFM produce an image of the outer ceramic matrix and thus complement the XRD and TEM observations which are sensitive to the denser crystalline metal component in the nanocomposite.

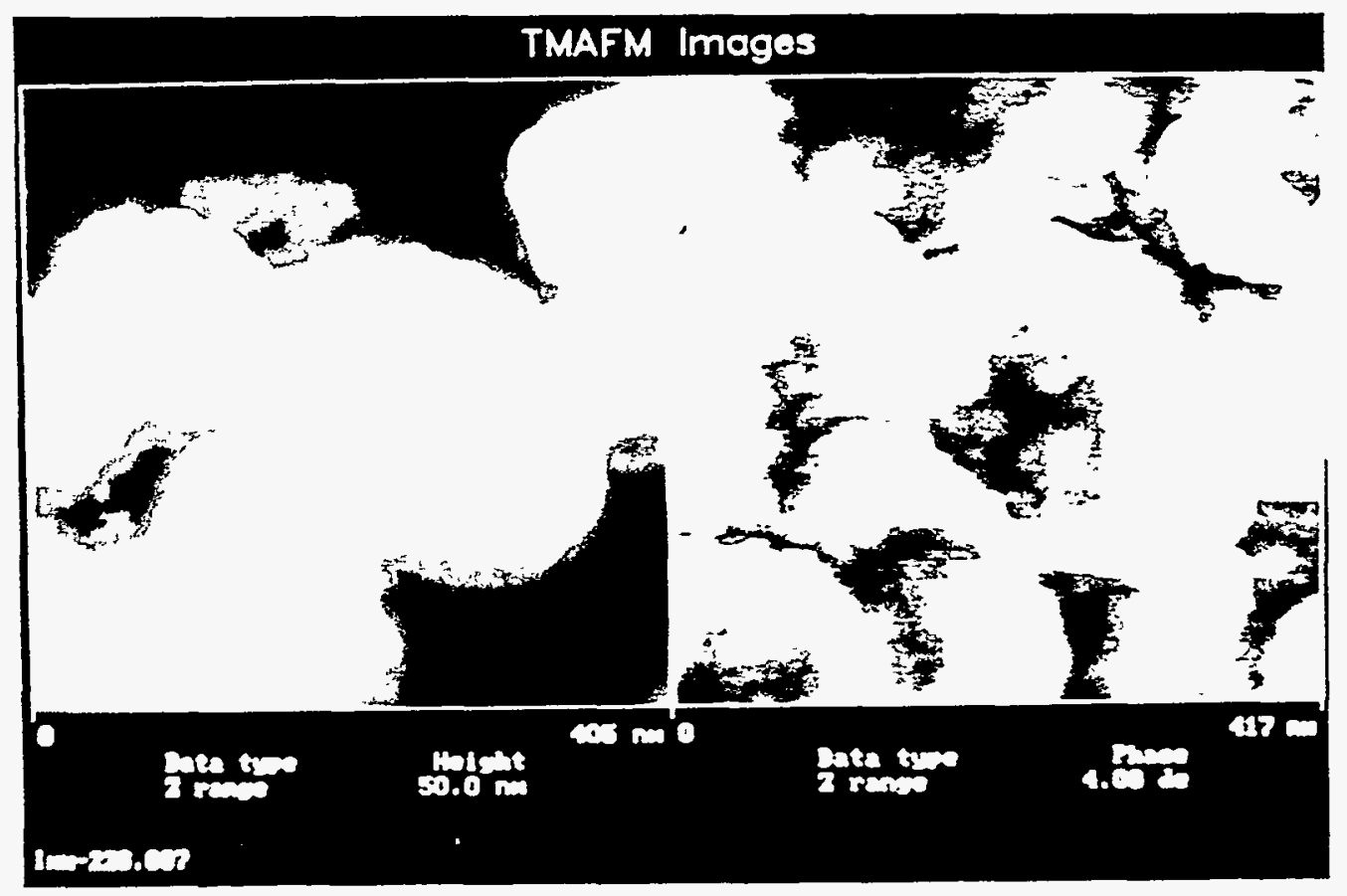

Fig. 4 Atomic force (left side) and magnetic force (right side) micrographs of Ni/AlN composite. Images are about $400 \mathrm{~nm}$ on the side.

\section{Data storage}

Localized heating, produced with a focused argon ion laser beam, was utilized to generate features a few microns in width which then could be imaged by MFM. This takes advantage of the fact that the areas not affected by the laser, containing the nitride which is paramagnetic, do not interact in the same manner with the magnetic tip of the microscope and produce a marked contrast. This constitutes a proof of principle that these systems may be utilized for ultrahigh 
density data storage once a method to generate smaller features is developed. One possible approach is to use the tip of the microscope as the heating source.

The long term stability is of concern for a successful data storage medium. Exposure to ambient air for a few months have shown that the aluminum nitride and silicon nitride matrixes remain unchanged and in the case of nickel nanocomposite no nickel oxide was detected by XRD. On the other hand, boron nitride was found to undergo partial hydrolytic decomposition.

\section{CONCLUSIONS}

The ferromagnetic nitrides in the form of nanocomposites in a ceramic matrix provide a media that through the use of localized heating may provide a useful data storage. Extended chemical stability for some of these systems seems to be adequate for practical use as recording media.

\section{ACKNOWLEDGMENT}

Research sponsored by the Division of Materials Sciences, Office of Basic Energy

Sciences, U.S. Department of Energy, under Contract No. DE-AC05-96OR22464 with Oak Ridge National Laboratory managed by Lockheed Martin Energy Research Corp.

\section{REFERENCES}

1. B. Abeles, P. Shoeing, M.D. Coutts, and Y. Arie, Adv. Phys. 24, 407 (1975).

2. C.L. Chien, J. Appl. Phys. 69, 5267 (1991).

3. L. Maya, W.R. Allen, A.L. Glover, and J.C. Mabon, J. Vac. Sci Technol. B 13, 361 (1995).

4. D. Kundu, I. Honma, T. Osawa, and H. Komiyama, J. Am. Ceram. Soc. 77, 1110 (1994).

5. K. Fukumi, A. Chayahara, K. Kadono, T. Sakaguchi, Y. Horino, M. Miya, J. Hayakawa, and M. Satou, Jpn. J. Appl. Phys. B 30, L742 (1991).

6. L. Maya, J. Vac. Sci. Technol. A 11, 604 (1993).

7. K. Suzuki, T. Kaneko, H. Yoshida, H. Morita, and H. Fujimori, J. Alloys Comp. 224, 232 (1995).

8. K. Suzuki, H. Morita, T. Kaneko, H. Yoshida, and H. Fujimori, J. Alloys Comp. 201. 11 (1993).

9. D. Cullity, Introduction to Magnetic Materials, Addison-Wesley, Reading, MA, 1972, pp. 386417.

10. H. E. Schaefer, H. Kisker, H. Krommuller, and R. Wurschum, NanoStruct. Mater. 1, 523 (1992). 